\title{
Causally Associations of Blood Lipids Levels with COVID- 19 Risk: Mendelian Randomization Study
}

\author{
Kun Zhang \\ Xi'an Jiaotong University \\ Yan Guo \\ Xi'an Jiaotong University \\ Zhuoxin Wang \\ Xi'an Jiaotong University \\ Jingmiao Ding \\ Xi'an Jiaotong University \\ Shi Yao \\ Xi'an Jiaotong University \\ Hao Chen \\ Xi'an Jiaotong University \\ Dongli Zhu \\ Xi'an Jiaotong University \\ Kun Zhang \\ Honghui Hospital \\ Hanzhong Xue \\ Honghui Hospital \\ Wei Huang \\ Honghui Hospital \\ Shanshan Dong \\ Xi'an Jiaotong University \\ Tielin Yang ( $\nabla$ yangtielin@xjtu.edu.cn ) \\ Xi'an Jiaotong University
}

Original investigation

Keywords: Blood lipids, COVID-19, Mendelian randomization, ABO blood group

Posted Date: October 9th, 2020

DOI: https://doi.org/10.21203/rs.3.rs-86425/v1

License: (c) (i) This work is licensed under a Creative Commons Attribution 4.0 International License. Read Full License 


\section{Abstract}

\section{Background}

Coronavirus disease 2019 (COVID-19) is a global pandemic caused by the severe acute respiratory syndrome coronavirus 2 (SARS-Cov-2). It has been found that coronary artery disease (CAD) is a comorbid condition for COVID19. As the risk factors of $C A D$, whether blood lipids levels are causally related to increasing susceptibility and severity of COVID-19 is still unknown.

\section{Objective}

We aim to measure the causal effects between blood lipids and COVID-19 using two-sample Mendelian Randomization (MR) methods.

\section{Methods}

We performed two-sample MR analyses to explore whether dyslipidemia, low density lipoprotein cholesterol (LDL-C), high density lipoprotein cholesterol (HDL-c), triglyceride (TG) and total cholesterol (TC) were causally related to COVID-19 risk and severity. The GWAS summary data of blood lipids involving in 312571 individuals and dyslipidemia in a total of 53991 individuals were used as exposures, respectively. Two COVID-19 GWASs including 1221 infected patients and 1610 severe patients defined as respiratory failure were employed as outcomes.

\section{Results}

The MR results showed that dyslipidemia was casually associated with the susceptibility of COVID-19 and induced $27 \%$ higher odds for COVID-19 infection (MR-IVW OR $=1.27,95 \% \mathrm{Cl}$ : 1.08 to $1.49, p$-value $=3.18 \times 10^{-3}$ ). For blood lipids, the increasing level of TC will raise $18 \%$ higher odds for the susceptibility of COVID-19 (MR-IVW OR $=1.18$, $95 \% \mathrm{Cl}: 1.06$ to $1.31, p$-value $\left.=3.08 \times 10^{-3}\right)$. Based on MR estimates, we further carried out gene-based analysis and found that $A B O$ gene was associated with TC.

\section{Conclusions}

Dyslipidemia is casually associated with the susceptibility of COVID-19 and the blood TC level is a risk factor for the susceptibility of COVID-19. In addition, the different susceptibility of COVID-19 in specific blood group may be partly explained by the TC concentration in diverse ABO blood groups.

\section{Background}

Coronavirus disease 2019 (COVID-19) caused by the severe acute respiratory syndrome, coronavirus 2 (SARS-Cov-2) is a global pandemic $[1,2]$. This disease progresses from asymptomatic to acute respiratory distress syndrome and multiple organ dysfunction, and has become a major threat to public health in more than 160 countries [1, 2]. As of Sep 26, 2020, there were more than 32.6 million confirmed cases, with total deaths increasing to 989761 worldwide. Considering the severity of COVID-19, it is urgent to explore the susceptibility factors of COVID-19, which is helpful to develop effective policies and personalized treatments to control the spread of the disease to susceptible groups.

Recent studies [1,2] have found that more than $20 \%$ of the confirmed cases had a history of coronary artery disease (CAD). Blood lipids, including low density lipoprotein cholesterol (LDL-c), high density lipoprotein cholesterol (HDL-c), 
triglyceride (TG) and total cholesterol (TC) are heritable and modifiable risk factors for CAD [3, 4]. However, whether blood lipids levels are causally related to increasing susceptibility and severity for COVID-19 is still unknown.

Mendelian randomization (MR) is an epidemiological method in which environmental exposure-related genetic variations are used as instrumental variables (IVs) to evaluate the association between exposures and outcomes [5, 6]. It can avoid the issues of confusion and has been demonstrated as an effective strategy to identify causal effect [5-10]. In this study, we conducted a two-sample Mendelian randomization study to explore the possible causal associations between blood lipids and COVID-19 susceptibility and severity, and investigate the potential mechanisms underlying the causal effect.

\section{Methods}

A step-by-step workflow in this study is presented in Fig. 1.

\section{Datasets used in this study}

\section{Blood lipids}

We collected the data of HDL-C, LDL-C, TG and TC from a published genome-wide association study (GWAS) [11] involving in a total of 312571 individuals (the proportion of European-ancestry: $73.74 \%$ ). The GWAS summary data of dyslipidemia, defined as the disorders of lipoid metabolism (ICD-9 code: 272), was obtained from the Genetic Epidemiology Research on Adult Health and Aging (GERA) (https://cnsgenomics.com/content/data) with 53991 European individuals [10].

\section{COVID-19}

For assessment of associations with COVID-19 risk, we used the latest COVID-19 GWAS results from GRASP database (https://grasp.nhlbi.nih.gov/Covid19GWASResults.aspx). The phenotype used in this GWAS was case/control for COVID-19 infection containing 1221 positive COVID-19 tests and 4117 negative tests from UK Biobank individuals (released on June 5, 2020). To explore the causal effect of blood lipids on severity of COVID-19, we also accessed GWAS of severe COVID-19 defined as respiratory failure [12] (http://www.c19-genetics.eu/). This GWAS included 1610 severe COVID-19 patients and 2205 control participants from Italy and Spain. These two GWASs were all conducted with the correction of age, sex and top 10 principal components.

\section{SNPs Filter and Data Standardization}

For each exposure GWAS, we filtered single nucleotide polymorphisms (SNPs) and standardized effect size using the following criteria:

1) Remove the SNPs located in major histocompatibility complex (MHC) region.

2) Select the SNPs with a common frequency of the effect allele (EAF) $(>0.01$ and $<0.99)$.

3) Standardize the effect size ( $\beta$ ) and standard error (se) for each GWAS data with the function of minor allele frequency and sample size using the following formula [13]:

$$
\beta=\frac{z}{\sqrt{2 p(1-p)\left(\mathrm{n}+z^{2}\right)}}, s e=\frac{1}{\sqrt{2 p(1-p)\left(\mathrm{n}+z^{2}\right)}}
$$


where $z=\beta$ /se from the original summary data, $p$ is the minor allele frequency, and $\mathrm{n}$ is the total sample size.

\section{Instrumental variables (IVs) selection}

We selected independent and genome-wide significant GWAS SNPs of HDL-C, LDL-C, TG, TC and dyslipidemia by use of the clumping algorithm in PLINK (http://pngu.mgh.harvard.edu/purcell/plink/) [14] at a suggestive threshold ( ${ }^{2}$ threshold $=0.001$, window size $=1 \mathrm{Mb}, p$-value $=5 \times 10^{-8}$ ). The 1000 Genomes Project (http://www.internationalgenome.org/) data were used as the reference for linkage disequilibrium (LD) estimation. For each outcome, we harmonize the data according to the SNPs included in COVID-19 GWAS and their effect allele. After data harmonization, we then removed outlier pleiotropic SNPs using RadialMR [15] with the $p$-value threshold of 0.05. RadialMR [15] identified outlying genetic instruments via heterogeneity test (modified Q-statistics). After the removal of pleiotropy, the remaining exposure related SNPs for each outcome as instrumental variables (IVs) were utilized to perform MR analyses.

\section{MR analyses and pleiotropy assessment}

We conducted four complementary two-sample MR methods, including Inverse-Variance Weighted (IVW) method, weighted median method, weighted mode method and MR-Egger method, which make different assumptions about horizontal pleiotropy.

The IVW method assumes balanced pleiotropy [16]. The pleiotropy is assessed via Cochran's $Q$ statistic and presented as excessive heterogeneity which will inflate the estimate of MR analysis [17]. MR-Egger is based on the assumption which indicate instrument strength independent of the direct effects [16]. It can be evaluated by the regression dilution $\mathrm{I}^{2}(\mathrm{GX})$ [18] according to the assumption that no measurement error (NOME) in the SNP exposure effects. $I^{2}(G X)$ is an adaptative $I^{2}$ statistic which propose to quantify the strength of NOME violation for MR-Egger method. If $\mathrm{I}^{2}(\mathrm{GX})$ [18] was sufficiently low $\left(\mathrm{I}^{2}(\mathrm{GX})<0 \cdot 9\right)$, the correction analysis was conducted to assess the causal effect by SIMEX, which can substantially mitigate adverse effects by simulation extrapolation[18]. The intercept term of MR-Egger method can used for evaluating the directional pleiotropic effect [19]. When the intercept is zero or its $p$ value was not significant ( $p$-value $>0.05$ ) were considered as non-pleiotropy. Moreover, we also used the Rucker's Q $\nabla$ statistic [20] to measure the heterogeneity for MR-Egger method. If the difference Q - Q $\mathbb{Q}$ is sufficiently extreme with respect to a $\chi 2$ distribution with the 1 degree of freedom, we indicated that directional pleiotropy is an important factor and MR-Egger model provides a better fit than the IVW method [21]. All methods of two-sample MR analyses were measured by TwoSampleMR package in R. For various estimates for different measures, we select the main MR method as following rules:

1) If no directional pleiotropy in MR estimates (Q statistic: $p$-value $>0.05$, MR-Egger intercept: intercept $=0$ or $p$-value $>0.05, \mathrm{Q}-\mathrm{Q}$ : $p$-value >0.05), IVW method was used.

2) If directional pleiotropy was detected (MR-Egger intercept: intercept $\neq 0$ and $p$-value $<0.05, Q-Q^{\prime}: p$-value $<0.05$ ) and $p$-value $>0.05$ for the test of Q', MR-Egger method was used.

3) If directional pleiotropy was detected (MR-Egger intercept: intercept $\neq 0$ and $p$-value $<0.05, Q-Q$ ': $p$-value $<0.05$ ) and $p$-value $<0.05$ for the test of $Q^{\prime}$, weighted median method was used.

\section{Sensitivity analysis}


Leave-one-out sensitivity analysis was implemented to assess whether any significant results were generated by a specific SNP in IVW models.

\section{Gene-based analysis}

MAGMA (https://ctg.cncr.nl/software/magma) [22] is commonly used for gene and gene-set analyses based on GWAS and genotype data. In order to explore the association of TC and COVID-19, we implemented MAGMA to identify genes and gene sets in which multiple SNPs show moderate association to TC without reaching the stringent genome-wide significance level. The genome-wide gene-based association study (GWGAS) is based on the model of multiple linear principal components regression and calculated the gene p-value using F-test [23]. All 19427 proteincoding genes from the NCBI 37.3 gene definitions were employed for SNPs annotation. We mapped SNPs to genes by

a defined window around each gene of $2 \mathrm{~kb}$ away from the transcription start site (TSS) upstream and $1 \mathrm{~kb}$ away from the transcription stop site downstream based on human reference assembly (GRCh37 or hg19) [24]. The GWGAS analysis was performed to quantify the degree of association for each gene to TC and to compute the correlations between genes are estimated according to LD statistics. The LD reference was also from Phase 3 of 1000 Genomes.

\section{Multiple testing correction}

We employed false discovery rate (FDR) to address multiple comparisons issue and the adjusted $p$-value $<0.05$ was used for judging significance. For MR estimates, we adopted an FDR control procedure for the susceptibility and severity of COVID-19 separately.

\section{Results}

\section{IVs selection}

After clumping, we identified 20, 909, 1167, 611 and 1163 independent SNPs significantly associated with dyslipidemia, HDL-C, LDL-C, TG and TC, respectively. After harmonizing with outcomes, there were 19 SNPs for dyslipidemia, 182 SNPs for HDL-C, 139 SNPs for LDL-C, 151 SNPs for TG and 150 SNPs for TC were remained as preIVs for RadialMR and obtained final IVs for MR analyses. The detailed information of these SNPs is represented in Table S1. For each outcome, the final IVs after RadialMR are shown in Table S2.

\section{Causal effect of dyslipidemia on COVID-19}

We evaluated whether dyslipidemia is causally related to COVID-19 firstly. The assessment of pleiotropy is shown in Table S1. Since there was no significant evidence of pleiotropy (all $p$-value $>0.05$, Table S3), we chose IVW as the main MR method. Moreover, $I^{2}(G X)$ showed the MR-Egger estimates didn't need to correct with SIMEX (all $I^{2}(G X)>$ 0.9 , Table S3). We found that dyslipidemia was causally associated with the susceptibility of COVID-19 after FDR correction (MR-IVW p-value $\left.=3.18 \times 10^{-3}, \mathrm{FDR}=7.50 \times 10^{-3}\right)($ Table 1$)$. The estimate of IVW showed that dyslipidemia could raise $27 \%$ odds for the infection risk of COVID-19 (MR-IVW OR =1.27, 95\% Cl: 1.08 to 1.49) (Fig. 2). Besides the IVW method, the weighted median and MR-Egger tests also showed consistent causal associations (MR-Weighted median OR $=1.26,95 \% \mathrm{Cl}$ : 1.01 to $1.56, p$-value $=4.00 \times 10^{-2}$; MR-Egger OR $=1.53,95 \% \mathrm{Cl}: 1.12$ to $2.10, p$-value $=2.00$ $\times 10^{-2}$ ) $($ Table 1$)$. However, dyslipidemia had no causally relevance to severe COVID-19 (Table 1 and Fig. 2). In sensitivity analyses, the results of leave-one-out permutation didn't find individual influential SNPs in IVW models ( $p$ value<0.05) (Figure S1). 
Table 1

Summary of the MR estimates for dyslipidemia, TC, TG, LDL-C and HDL-c to the susceptibility and severity of COVID$19^{1}$

\begin{tabular}{|c|c|c|c|c|c|c|c|c|c|c|}
\hline \multirow[t]{2}{*}{ Lipid } & \multicolumn{2}{|c|}{ IVW method } & \multicolumn{2}{|c|}{$\begin{array}{l}\text { Weighted } \\
\text { median method }\end{array}$} & \multicolumn{2}{|c|}{$\begin{array}{l}\text { Weighted mode- } \\
\text { based method }\end{array}$} & \multicolumn{2}{|c|}{$\begin{array}{l}\text { MR-Egger } \\
\text { method }\end{array}$} & \multirow[t]{2}{*}{$\begin{array}{l}\text { Main } \\
\text { method }\end{array}$} & \multirow[t]{2}{*}{ FDR } \\
\hline & $\begin{array}{l}\text { OR } \\
(95 \% \mathrm{Cl})\end{array}$ & $p$ & $\begin{array}{l}\text { OR } \\
(95 \% \mathrm{Cl})\end{array}$ & $p$ & $\begin{array}{l}\text { OR } \\
(95 \% \mathrm{Cl})\end{array}$ & $p$ & $\begin{array}{l}\text { OR } \\
(95 \% \mathrm{Cl})\end{array}$ & $p$ & & \\
\hline \multicolumn{11}{|l|}{ COVID-19 } \\
\hline Dyslipidemia & $\begin{array}{l}1.27 \\
(1.08, \\
1.49)\end{array}$ & 0.003 & $\begin{array}{l}1.26 \\
(1.01 \\
1.56)\end{array}$ & 0.040 & $\begin{array}{l}1.22 \\
(0.93 \\
1.61)\end{array}$ & 0.171 & $\begin{array}{l}1.53 \\
(1.12 \\
2.10)\end{array}$ & 0.020 & IVW & $\begin{array}{l}7.50 \\
\times \\
10^{-3}\end{array}$ \\
\hline $\begin{array}{l}\text { Total } \\
\text { Cholesterol }\end{array}$ & $\begin{array}{l}1.18 \\
(1.06 \\
1.31)\end{array}$ & 0.003 & $\begin{array}{l}1.20 \\
(1.00 \\
1.43)\end{array}$ & 0.044 & $\begin{array}{l}1.23 \\
(1.04 \\
1.45)\end{array}$ & 0.015 & $\begin{array}{l}1.21 \\
(1.02 \\
1.43)\end{array}$ & 0.033 & IVW & $\begin{array}{l}7.50 \\
\times \\
10^{-3}\end{array}$ \\
\hline Triglycerides & $\begin{array}{l}1.03 \\
(0.91 \\
1.16)\end{array}$ & 0.620 & $\begin{array}{l}1.09 \\
(0.89 \\
1.32)\end{array}$ & 0.416 & $\begin{array}{l}1.13 \\
(0.95 \\
1.36)\end{array}$ & 0.171 & $\begin{array}{l}1.16 \\
(0.95 \\
1.42)\end{array}$ & 0.140 & IVW & $\begin{array}{l}6.20 \\
\times \\
10^{-1}\end{array}$ \\
\hline $\begin{array}{l}\text { LDL } \\
\text { Cholesterol }\end{array}$ & $\begin{array}{l}1.07 \\
(0.95 \\
1.20)\end{array}$ & 0.269 & $\begin{array}{l}1.14 \\
(0.95 \\
1.38)\end{array}$ & 0.164 & $\begin{array}{l}1.07 \\
(0.89 \\
1.27)\end{array}$ & 0.472 & $\begin{array}{l}1.04 \\
(0.87 \\
1.24)^{\prime}\end{array}$ & 0.648 & IVW & $\begin{array}{l}4.40 \\
\times \\
10^{-1}\end{array}$ \\
\hline $\begin{array}{l}\text { HDL } \\
\text { Cholesterol }\end{array}$ & $\begin{array}{l}1.05 \\
(0.94 \\
1.17)\end{array}$ & 0.352 & $\begin{array}{l}1.10 \\
(0.93 \\
1.3)\end{array}$ & 0.254 & $\begin{array}{l}1.18 \\
(0.93 \\
1.49)\end{array}$ & 0.178 & $\begin{array}{l}1.15 \\
(0.95 \\
1.39)\end{array}$ & 0.144 & IVW & $\begin{array}{l}4.40 \\
\times \\
10^{-1}\end{array}$ \\
\hline \multicolumn{11}{|l|}{$\begin{array}{l}\text { Severe } \\
\text { COVID-19 }\end{array}$} \\
\hline Dyslipidemia & $\begin{array}{l}0.83 \\
(0.67 \\
1.02)\end{array}$ & 0.071 & $\begin{array}{l}0.81 \\
(0.62 \\
1.07)\end{array}$ & 0.139 & $\begin{array}{l}0.83 \\
(0.60 \\
1.14)\end{array}$ & 0.267 & $\begin{array}{l}0.69 \\
(0.44 \\
1.06)\end{array}$ & 0.112 & IVW & $\begin{array}{l}3.55 \\
\times \\
10^{-1}\end{array}$ \\
\hline $\begin{array}{l}\text { Total } \\
\text { Cholesterol }\end{array}$ & $\begin{array}{l}1.01 \\
(0.89 \\
1.16)\end{array}$ & 0.824 & $\begin{array}{l}0.98 \\
(0.80 \\
1.20)\end{array}$ & 0.816 & $\begin{array}{l}0.98 \\
(0.79 \\
1.21)^{\prime}\end{array}$ & 0.847 & $\begin{array}{l}0.90 \\
(0.73 \\
1.11)\end{array}$ & 0.334 & IVW & $\begin{array}{l}8.24 \\
\times \\
10^{-1}\end{array}$ \\
\hline Triglycerides & $\begin{array}{l}1.12 \\
(0.99 \\
1.27)^{\prime}\end{array}$ & 0.074 & $\begin{array}{l}1.04 \\
(0.85 \\
1.27)\end{array}$ & 0.706 & $\begin{array}{l}1.03 \\
(0.87 \\
1.21)\end{array}$ & 0.757 & $\begin{array}{l}0.95 \\
(0.79 \\
1.16)\end{array}$ & 0.627 & $\begin{array}{l}\text { MR- } \\
\text { Egger }\end{array}$ & $\begin{array}{l}7.84 \\
\times \\
10^{-1}\end{array}$ \\
\hline $\begin{array}{l}\text { LDL } \\
\text { Cholesterol }\end{array}$ & $\begin{array}{l}0.96 \\
(0.84 \\
1.10)\end{array}$ & 0.568 & $\begin{array}{l}0.92 \\
(0.73 \\
1.14)\end{array}$ & 0.439 & $\begin{array}{l}0.92 \\
(0.76, \\
1.12)\end{array}$ & 0.423 & $\begin{array}{l}0.88 \\
(0.72 \\
1.06)\end{array}$ & 0.181 & IVW & $\begin{array}{l}7.84 \\
\times \\
10^{-1}\end{array}$ \\
\hline $\begin{array}{l}\text { HDL } \\
\text { Cholesterol }\end{array}$ & $\begin{array}{l}0.92 \\
(0.81 \\
1.04)\end{array}$ & 0.170 & $\begin{array}{l}0.99 \\
(0.81 \\
1.2)\end{array}$ & 0.889 & $\begin{array}{l}1.01 \\
(0.81 \\
1.26)\end{array}$ & 0.923 & $\begin{array}{l}1.01 \\
(0.82 \\
1.25)\end{array}$ & 0.909 & IVW & $\begin{array}{l}4.25 \\
\times \\
10^{-1}\end{array}$ \\
\hline $\begin{array}{l}{ }^{1} \text { Results desc } \\
\text { and weighted } \\
\text { (COVID-19) an } \\
\text { of FDR }<0.05\end{array}$ & $\begin{array}{l}\text { he sevel } \\
\text { marked }\end{array}$ & $\begin{array}{l}\text { of COI } \\
\text { bold. }\end{array}$ & $\begin{array}{l}\text { rived frol } \\
\text { for dyslip } \\
-19 \text { (Sev } \\
\text {-value; }\end{array}$ & $\begin{array}{l}\text { the ma } \\
\text { emia, } 1 \\
\text { e COVII } \\
\text { confide }\end{array}$ & $\begin{array}{l}\text { inverse-v } \\
\text { L-c, LDL- } \\
\text { 9). FDR } \\
\text { e interva }\end{array}$ & $\begin{array}{l}\text { ance v } \\
\text { TC anc } \\
\text { ers to }\end{array}$ & $\begin{array}{l}\text { ghted, } M \\
3 \text { to the } \\
p \text {-value }\end{array}$ & $\begin{array}{l}\text { Egger, v } \\
\text { sceptib } \\
\text { m mai }\end{array}$ & $\begin{array}{l}\text { ghted m } \\
y \text { of COV } \\
\text { nethod. }\end{array}$ & $\begin{array}{l}\text { lian } \\
-19 \\
\text { alues }\end{array}$ \\
\hline
\end{tabular}




\section{Causal effect of blood lipids on COVID-19}

We further assessed the causal effects of blood lipids levels, including HDL-C, LDL-C, TC and TG on COVID-19 to identify the specific risk lipid. According to the evidence of pleiotropy (Table S3), we chose IVW as main MR method except TG to the severity of COVID-19 (MR-Egger intercept: $p$-value<0.05, Q-Q': $p$-value< 0.05). Besides, $I^{2}$ (GX) also indicated the MR-Egger estimates didn't need to correct with SIMEX (all I ${ }^{2}(G X)>0.9$, Table S3). We identified TC was a risk factor for the susceptibility of COVID-19 (MR-IVW p-value $=3.08 \times 10^{-3}, \mathrm{FDR}=7.50 \times 10^{-3}$ ) $($ Table 1 ). As shown in Fig. 2, the increasing concentration of TC in blood could induce 18\% higher odds of COVID-19 infection risk (MRIVW OR $=1.18,95 \% \mathrm{Cl}$ : 1.06 to 1.31). Besides, other three methods also showed a potential causal association (MRWeighted median $\mathrm{OR}=1.20,95 \% \mathrm{Cl}: 1.00$ to $1.43, p$-value $=4.39 \times 10^{-2}$; Weight mode-based OR $=1.23,95 \% \mathrm{Cl}: 1.04$ to $1.45, p$-value $=1.50 \times 10^{-2}$; MR-Egger OR $=1.21,95 \% \mathrm{Cl}: 1.02$ to $1.43, p$-value $\left.=3.29 \times 10^{-2}\right)($ Table 1$)$. Leave-one-out analysis indicated that no single SNP was driving the causal estimates (Figure S2). We also measured the relationship between four blood lipids and severe COVID-19. Consistent with dyslipidemia, there was no causal effects for blood lipids-COVID-19 severity pairs.

\section{Gene-based analyses}

In our above results, we have discovered the risk effect of TC to the susceptibility of COVID-19. We wonder explain the internal linkage between TC and LDL-C to COVID-19 preliminarily, thus we investigated the potential mechanism of TC and LDL-c by gene-based analysis.

For gene-based analysis, a total of 17699 genes which were represented by at least one SNP were identified. After correction for multiple testing, we identified 1642 genes linked to TC (Fig. 3A, and Table S4). It should be noticed that $A B O$ was identified to be associated with TC significantly ( $p$-value $=1.14 \times 10^{-15}$, FDR $\left.=2.53 \times 10^{-13}\right)$. Some observational studies have found that the level of blood lipids was related to ABO blood group and Table 2 lists the detailed information about these observational studies [25-30]. All of these studies provide a conclusion that TC is higher in A or non-O blood group, but lower in O blood group. On the other side, GWAS on severe COVID-19 has revealed the relationship between ABO blood group locus and COVID-19 [12]. It has been found a higher risk in blood group $A$ than in other blood group and a protective effect in blood group 0 , which was coincident with the results of observational investigations based on phenotype [31, 32]. In general, we inferred that the different susceptibility of COVID-19 in specific blood group may be partly explained by the TC levels in diverse ABO blood group (Fig. 3B). 
Table 2

Summary of the observational studies for TC and LDL-c level in different ABO blood group ${ }^{1}$

\begin{tabular}{|c|c|c|c|c|c|c|}
\hline Subjects & Cohort & $\begin{array}{l}\text { Sample } \\
\text { size }\end{array}$ & $\begin{array}{l}\text { ABO } \\
\text { blood } \\
\text { groups }\end{array}$ & $\begin{array}{l}\text { Level of blood } \\
\text { lipids (Mean } \pm \\
\text { SE/SD) }\end{array}$ & $\begin{array}{l}p- \\
\text { value }\end{array}$ & Description \\
\hline $\begin{array}{l}\text { Healthy blood } \\
\text { donors }\end{array}$ & Italian & 7723 & $\begin{array}{l}\text { A vs. } 0 \\
(\mathrm{mg} / \mathrm{dL})\end{array}$ & $\begin{array}{l}(183.95 \pm 0.65) \\
\text { vs. }(181.31 \pm \\
0.64)\end{array}$ & $\begin{array}{l}4.00 \\
\times \\
10^{-3}\end{array}$ & $\begin{array}{l}\text { The values of TC and LDL-C } \\
\text { are significantly higher in } \\
\text { subjects with blood group A } \\
\text { compared with those with } 0 \\
\text { blood type [25]. }\end{array}$ \\
\hline CAD patients & Chinese & 6476 & $\begin{array}{l}\text { Non-O vs. } \\
\text { O } \\
(\mathrm{mmol} / \mathrm{L})\end{array}$ & $\begin{array}{l}(4.93 \pm 0.02) \text { vs. } \\
(4.78 \pm 0.03)\end{array}$ & $\begin{array}{l}3.80 \\
\times \\
10^{-7}\end{array}$ & $\begin{array}{l}\text { Subjects of non-O type had } \\
\text { higher levels of TC, LDL-C, } \\
\text { and NHDL-C }{ }^{[26]} \text {. }\end{array}$ \\
\hline $\begin{array}{l}\text { Acute STEMI } \\
\text { patients }\end{array}$ & European & 1835 & $\begin{array}{l}\text { Non-O vs. } \\
\text { O } \\
(\mathrm{mg} / \mathrm{dL})\end{array}$ & $\begin{array}{l}\mathrm{A}(180.40 \pm \\
34.50), \mathrm{B} \\
(182.10 \pm \\
35.10), \mathrm{AB} \\
(180.50 \pm 33.80) \\
\text { vs. } 0(175.30 \pm \\
33.20)\end{array}$ & $\begin{array}{l}2.30 \\
\times \\
10^{-2}\end{array}$ & $\begin{array}{l}\text { The prevalence of } \\
\text { hyperlipidemia, TC, LDL, } \\
\text { peak CKMB and no-reflow as } \\
\text { well as hospitalization } \\
\text { duration were higher in } \\
\text { patients with non-O blood } \\
\text { groups [27]. }\end{array}$ \\
\hline $\begin{array}{l}\text { Coronary } \\
\text { atherosclerosis } \\
\text { patients }\end{array}$ & Chinese & 371 & $\begin{array}{l}\text { Non-O vs. } \\
\text { O } \\
(\mathrm{mmol} / \mathrm{L})\end{array}$ & $\left(\begin{array}{l}5.07 \pm 1.14) v s . \\
1.78 \pm 1.01)\end{array}\right.$ & $\begin{array}{l}4.00 \\
\times \\
10^{-3}\end{array}$ & $\begin{array}{l}\text { Subjects of non-O type had } \\
\text { higher levels of TC, LDL-C } \\
\text { and NHDL-C compared with } \\
\text { that of O type [28]. }\end{array}$ \\
\hline \multirow[t]{2}{*}{ Adolescents } & White & 4460 & $\begin{array}{l}A_{1} \text { vs. } 0 \\
(m g / d L)\end{array}$ & $\begin{array}{l}\text { Males: }(174.20 \\
\pm 0.90) \text { vs. } \\
(170.70 \pm 0.80)\end{array}$ & $\begin{array}{l}5.00 \\
\times \\
10^{-3}\end{array}$ & $\begin{array}{l}\text { Blood group A with higher } \\
\text { serum TC levels in white } \\
\text { adolescents [29]. }\end{array}$ \\
\hline & & & & $\begin{array}{l}\text { Females: } \\
(181.00 \pm 1.00) \\
\text { vs. }(176.10 \pm \\
0.90)\end{array}$ & $\begin{array}{l}3.00 \\
\times \\
10^{-4}\end{array}$ & \\
\hline FH patients & White & 668 & $\begin{array}{l}\text { Non-O vs. } \\
\text { O } \\
(\mathrm{mmol} / \mathrm{L})\end{array}$ & $\begin{array}{l}(9.48 \pm 1.69) \text { vs } \\
(9.14 \pm 1.73)\end{array}$ & $\begin{array}{l}2.00 \\
\times \\
10^{-2}\end{array}$ & $\begin{array}{l}\text { Total cholesterol was } \\
\text { significantly higher in non-0 } \\
\text { subjects compared to } \\
\text { carriers of the O group [30]. }\end{array}$ \\
\hline
\end{tabular}

\section{Discussion}

In this study, we implemented two-sample MR analyses to explore the possible causal associations between blood lipids and COVID-19. We have found potential causal effects of dyslipidemia and blood TC on the infected risk of COVID-19.

To explain the potential influence of TC on COVID-19, we explored the TC-related genes. It is notable that $A B O$ gene performs quite strong relevance to TC, which was also reported by previous GWAS of TC [4]. Besides, some observational studies have found that the blood lipids level was related to ABO blood group. The higher level of TC was found in non-O blood group and was significantly associated with an increased prevalence of CVD [25-30]. In addition, The GWAS of severe COVID-19 has identified the association signal at ABO blood group locus [12]. Based on the blood-group-specific analysis, they observed a higher risk of COVID-19 in blood group A than in other blood 
group and a protective effect in blood group 0 , which was coincident with the results of observational investigations based on phenotype [31, 32]. In summary of these results, we inferred that the different susceptibility of COVID-19 in specific blood group may be partly explained by the TC concentration in diverse ABO blood groups.

This is the first study to characterize the potential causality of blood lipids for the susceptibility and severity of COVID-19 using two-sample MR design rather than observational and perspective studies based on conventional association analysis. In the previous, Ponsford et al. [33] conducted MR analyses between cardiometabolic traits and COVID-19 which including LDL-C as exposure, and found that the result was not significant. It is consistent with our results. Our findings broaden the understanding of COVID-19 susceptibility and firstly address that the different susceptibility of COVID-19 in specific blood group may be partly explained by the TC levels in diverse ABO blood group, which may be helpful to develop effective instructions and policies to control the spread of the disease to susceptible groups. However, the limitations of the current study should be addressed. Due to the limitation of data resource, our findings are based on European cohort which cannot represent the universal conclusions for other ethnic groups. In addition, the potential mechanism of the risk effect for TC was discussed superficially, which needed to carry out further investigation to get more data support and further experimental verification.

\section{Conclusions}

In summary, we carried out a two-sample MR design for blood lipids and COVID-19, and obtained following exploratory conclusions: 1) Dyslipidemia is causally associated with the susceptibility of COVID-19; 2) The higher total cholesterol level will increase the susceptibility of COVID-19;3) The different susceptibility of COVID-19 in specific blood group may be partly explained by the TC concentration in diverse ABO blood groups.

\section{Abbreviations}

COVID-19: Coronavirus disease 2019

SARS-Cov-2: Severe acute respiratory syndrome coronavirus 2

CAD: Coronary artery disease

MR: Mendelian Randomization

LDL-c: Low density lipoprotein cholesterol

HDL-c: High density lipoprotein cholesterol

TC: Total cholesterol

TG: Triglyceride

IVs: Instrumental variables

GWAS: Genome-wide association study

SNP: Single nucleotide polymorphism

MHC: Major histocompatibility complex 
LD: Linkage disequilibrium

TSS: Transcription start site

FDR: False discovery rate

\section{Declarations}

\section{Ethics approval and consent to participate}

Not applicable.

\section{Consent for publication}

Not applicable.

\section{Availability of data and materials}

All data generated or analyzed during this study are included in this published article and its additional files.

\section{Acknowledgement}

Not applicable.

\section{Funding}

This study is supported by National Natural Science Foundation of China (31871264, 31970569); Zhejiang Provincial Natural Science Foundation of China (LGF18C060002); Shaanxi Provincial Key Research and Development Project (2019ZDLSF01-09), and the Fundamental Research Funds for the Central Universities.

\section{Contributions}

Yan Guo, and Kun Zhang contributed equally to this study. Tielin Yang, Shanshan Dong, Yan Guo, and Kun Zhang designed the study. Shi Yao, Zhuoxin Wang, and Jingmiao Ding collected data. Kun Zhang analyzed data. Kun Zhang, Shanshan Dong, Hanzhong Xue, Wei Huang, and Yan Guo interpreted the results. Kun Zhang wrote the Article. Yan Guo, Shanshan Dong, Tielin Yang, Hao Chen, and Dongli Zhu edited and revised the Article.

\section{Competing interests}

The authors declare no competing interests.

\section{References}

1. Guan W-J, Ni Z-Y, Hu Y, Liang W-H, Ou C-Q, He J-X, Liu L, Shan H, Lei C-L, Hui DSC et al: Clinical Characteristics of Coronavirus Disease 2019 in China. The New England journal of medicine 2020, 382(18):1708-1720.

2. Huang C, Wang Y, Li X, Ren L, Zhao J, Hu Y, Zhang L, Fan G, Xu J, Gu X et al: Clinical features of patients infected with 2019 novel coronavirus in Wuhan, China. Lancet (London, England) 2020, 395(10223):497-506.

3. WP C: Cholesterol and lipids in the risk of coronary artery disease-the Framingham Heart Study. The Canadian journal of cardiology 1988:5A-10A. 
4. Willer CJ, Schmidt EM, Sengupta S, Peloso GM, Gustafsson S, Kanoni S, Ganna A, Chen J, Buchkovich ML, Mora S et al: Discovery and refinement of loci associated with lipid levels. Nature Genetics 2013, 45(11):1274-1283.

5. Boef AGC, Dekkers OM, le Cessie S: Mendelian randomization studies: a review of the approaches used and the quality of reporting. International Journal of Epidemiology 2015, 44(2):496-511.

6. Sleiman PMA, Grant SFA: Mendelian Randomization in the Era of Genomewide Association Studies. Clinical Chemistry 2010, 56(5):723.

7. Davies NM, von Hinke Kessler Scholder S, Farbmacher H, Burgess S, Windmeijer F, Smith GD: The many weak instruments problem and Mendelian randomization. Stat Med 2015, 34(3):454-468.

8. Burgess S, Thompson SG, Collaboration CCG: Avoiding bias from weak instruments in Mendelian randomization studies. International Journal of Epidemiology 2011, 40(3):755-764.

9. Davey Smith G, Ebrahim S: 'Mendelian randomization': can genetic epidemiology contribute to understanding environmental determinants of disease?*. International Journal of Epidemiology 2003, 32(1):1-22.

10. Zhu Z, Zheng Z, Zhang F, Wu Y, Trzaskowski M, Maier R, Robinson MR, McGrath JJ, Visscher PM, Wray NR et al: Causal associations between risk factors and common diseases inferred from GWAS summary data. Nature communications 2018, 9(1):224-224.

11. Klarin D, Damrauer SM, Cho K, Sun YV, Teslovich TM, Honerlaw J, Gagnon DR, DuVall SL, Li J, Peloso GM et al: Genetics of blood lipids among 300,000 multi-ethnic participants of the Million Veteran Program. Nature Genetics 2018, 50(11):1514-1523.

12. Ellinghaus D, Degenhardt F, Bujanda L, Buti M, Albillos A, Invernizzi P, Fernández J, Prati D, Baselli G, Asselta R et al: Genomewide Association Study of Severe Covid-19 with Respiratory Failure. The New England journal of medicine 2020:NEJMoa2020283.

13. Zhu Z, Zhang F, Hu H, Bakshi A, Robinson MR, Powell JE, Montgomery GW, Goddard ME, Wray NR, Visscher PM et al: Integration of summary data from GWAS and eQTL studies predicts complex trait gene targets. Nature Genetics 2016, 48(5):481-487.

14. Purcell S, Neale B, Todd-Brown K, Thomas L, Ferreira MAR, Bender D, Maller J, Sklar P, de Bakker PIW, Daly MJ et al: PLINK: a tool set for whole-genome association and population-based linkage analyses. American journal of human genetics 2007, 81(3):559-575.

15. Bowden J, Spiller W, Del Greco M F, Sheehan N, Thompson J, Minelli C, Davey Smith G: Improving the visualization, interpretation and analysis of two-sample summary data Mendelian randomization via the Radial plot and Radial regression. International journal of epidemiology 2018, 47(4):1264-1278.

16. Bowden J, Davey Smith G, Burgess S: Mendelian randomization with invalid instruments: effect estimation and bias detection through Egger regression. International journal of epidemiology 2015, 44(2):512-525.

17. G CW: The combination of estimates from different experiments. Biometrics 1954, 10:28.

18. Bowden J, Del Greco M F, Minelli C, Davey Smith G, Sheehan NA, Thompson JR: Assessing the suitability of summary data for two-sample Mendelian randomization analyses using MR-Egger regression: the role of the 12 statistic. International journal of epidemiology 2016, 45(6):1961-1974.

19. Hemani G, Bowden J, Davey Smith G: Evaluating the potential role of pleiotropy in Mendelian randomization studies. Human molecular genetics 2018, 27(R2):R195-R208.

20. Rücker G, Schwarzer G, Carpenter JR, Binder H, Schumacher M: Treatment-effect estimates adjusted for smallstudy effects via a limit meta-analysis. Biostatistics 2010, 12(1):122-142.

21. Bowden J, Del Greco M F, Minelli C, Davey Smith G, Sheehan N, Thompson J: A framework for the investigation of pleiotropy in two-sample summary data Mendelian randomization. Stat Med 2017, 36(11):1783-1802. 
22. de Leeuw CA, Mooij JM, Heskes T, Posthuma D: MAGMA: generalized gene-set analysis of GWAS data. PLoS computational biology 2015, 11(4):e1004219-e1004219.

23. de Leeuw CA, Neale BM, Heskes T, Posthuma D: The statistical properties of gene-set analysis. Nature Reviews Genetics 2016, 17(6):353-364.

24. Nagel M, Jansen PR, Stringer S, Watanabe K, de Leeuw CA, Bryois J, Savage JE, Hammerschlag AR, Skene NG, Muñoz-Manchado AB et al: Meta-analysis of genome-wide association studies for neuroticism in 449,484 individuals identifies novel genetic loci and pathways. Nature Genetics 2018, 50(7):920-927.

25. Franchini M, Mengoli C, Capuzzo E, Terenziani I, Bonfanti C, Lippi G: Correlation between ABO Blood Group, and Conventional Hematological and Metabolic Parameters in Blood Donors. Semin Thromb Hemost 2016, 42(01):075-086.

26. Chen Y, Chen C, Ke X, Xiong L, Shi Y, Li J, Tan X, Ye S: Analysis of Circulating Cholesterol Levels as a Mediator of an Association Between ABO Blood Group and Coronary Heart Disease. Circulation: Cardiovascular Genetics 2014, 7(1):43-48.

27. Cetin MS, Ozcan Cetin EH, Aras D, Topaloglu S, Temizhan A, Kisacik HL, Aydogdu S: Non-O blood groups can be a prognostic marker of in-hospital and long-term major adverse cardiovascular events in patients with ST elevation myocardial infarction undergoing primary percutaneous coronary intervention. Thrombosis Research 2015, 136(3):599-605.

28. Li S, Xu R-X, Guo Y-L, Zhang Y, Zhu C-G, Sun J, Li J-J: ABO blood group in relation to plasma lipids and proprotein convertase subtilisin/kexin type 9. Nutrition, Metabolism and Cardiovascular Diseases 2015, 25(4):411-417.

29. Gillum RF: Blood groups, serum cholesterol, serum uric acid, blood pressure, and obesity in adolescents. Journal of the National Medical Association 1991, 83(8):682-688.

30. Paquette $M$, Dufour $R$, Baass $A$ : ABO blood group is a cardiovascular risk factor in patients with familial hypercholesterolemia. Journal of Clinical Lipidology 2018, 12(2):383-389.e381.

31. Wu Y, Feng Z, Li P, Yu Q: Relationship between ABO blood group distribution and clinical characteristics in patients with COVID-19. Clinica Chimica Acta 2020, 509:220-223.

32. Zietz M, Tatonetti NP: Testing the association between blood type and COVID-19 infection, intubation, and death. medRxiv : the preprint server for health sciences 2020:2020.2004.2008.20058073.

33. Ponsford Mark J, Gkatzionis A, Walker Venexia M, Grant Andrew J, Wootton Robyn E, Moore Luke SP, Fatumo S, Mason Amy M, Zuber V, Willer C et al: Cardiometabolic Traits, Sepsis and Severe COVID-19: A Mendelian Randomization Investigation. Circulation, $\mathbf{0}(0)$.

\section{Figures}




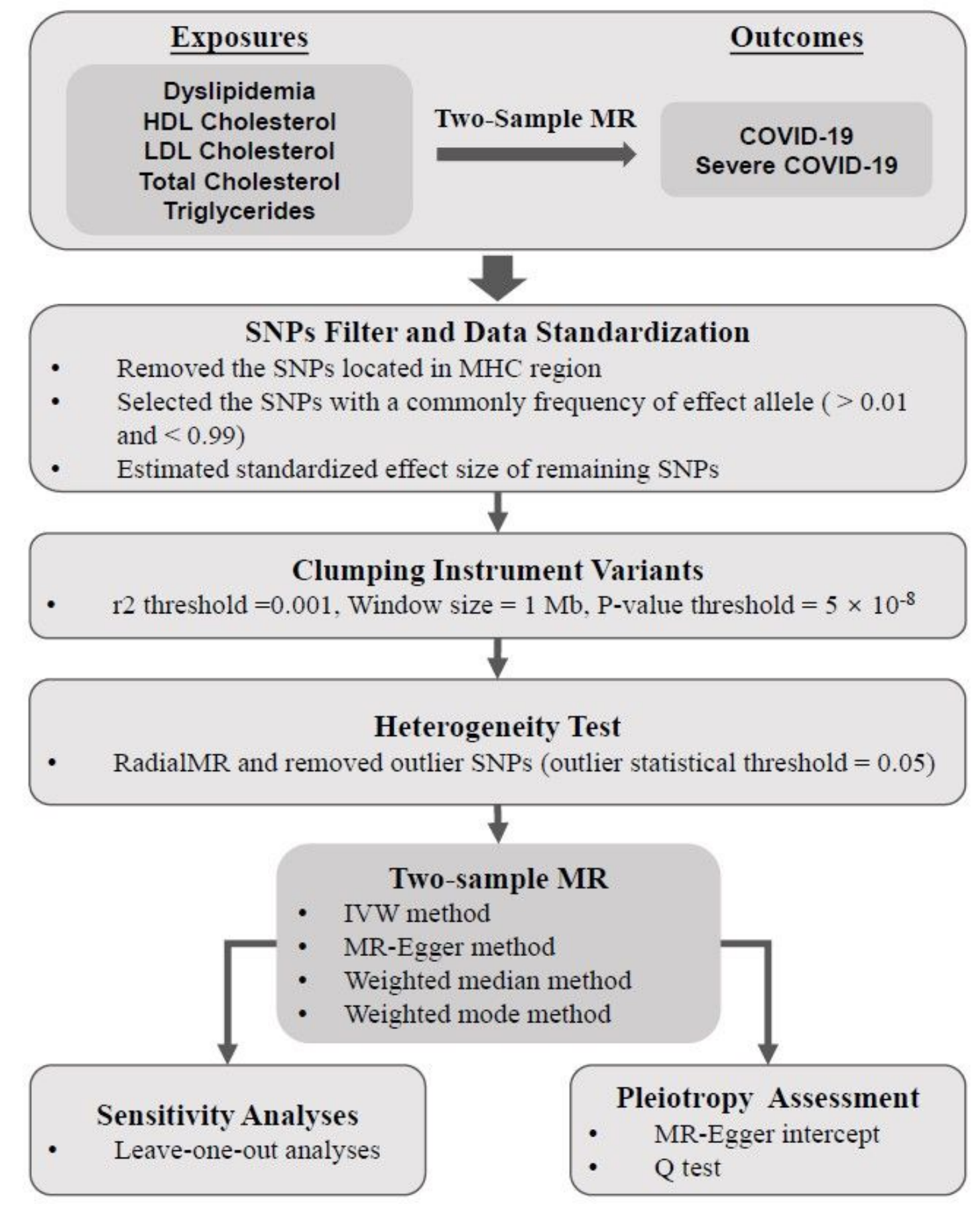

Figure 1

The MR analysis pipeline of the current study. 


\section{Dyslipidemia}

\section{Method}

Inverse variance weighted

Weighted median

Weighted mode

MR-Egger

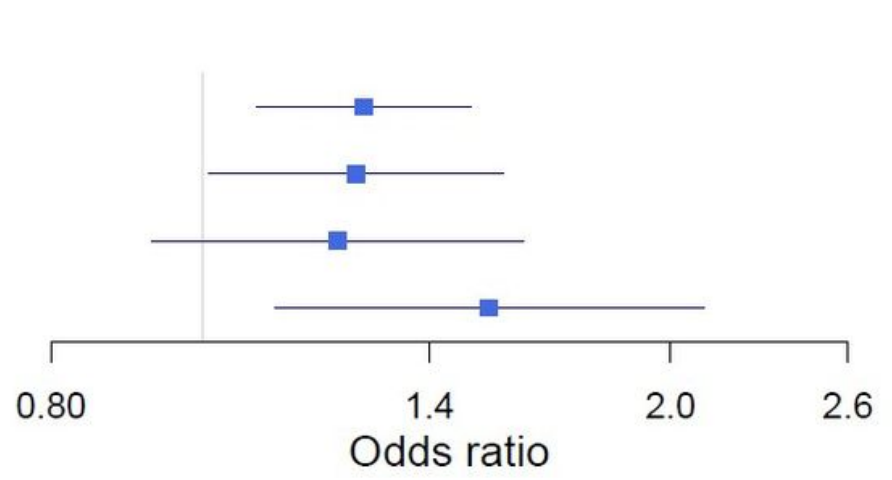

Odds ratio $(95 \% \mathrm{Cl})$

1.27 (1.08 to 1.49)

1.26 (1.01 to 1.56$)$

1.22 (0.93 to 1.61$)$

1.53 (1.12 to 2.10$)$

\section{Total Cholesterol}

\section{Method}

Inverse variance weighted

Weighted median

Weighted mode

MR-Egger

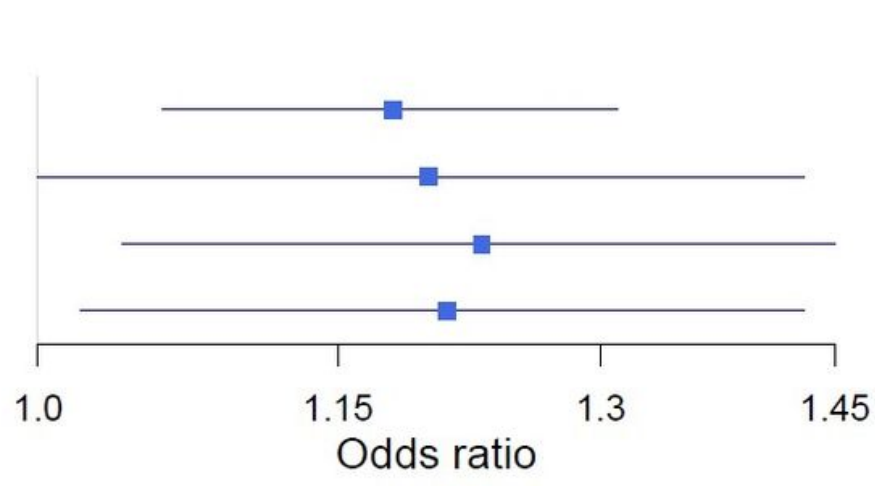

Odds ratio $(95 \% \mathrm{Cl})$

1.18 (1.06 to 1.31 )

1.20 (1.00 to 1.43 )

1.23 (1.04 to 1.45$)$

1.21 (1.02 to 1.43$)$

\section{Figure 2}

Causal effects of dyslipidemia and TC on COVID-19. Summary of the Mendelian randomization (MR) estimates derived from the main inverse-variance weighted, MR-Egger, weighted median and weighted mode-based methods for dyslipidemia and TC to the susceptibility of COVID-19 (COVID-19). 
A.

Total Cholesterol

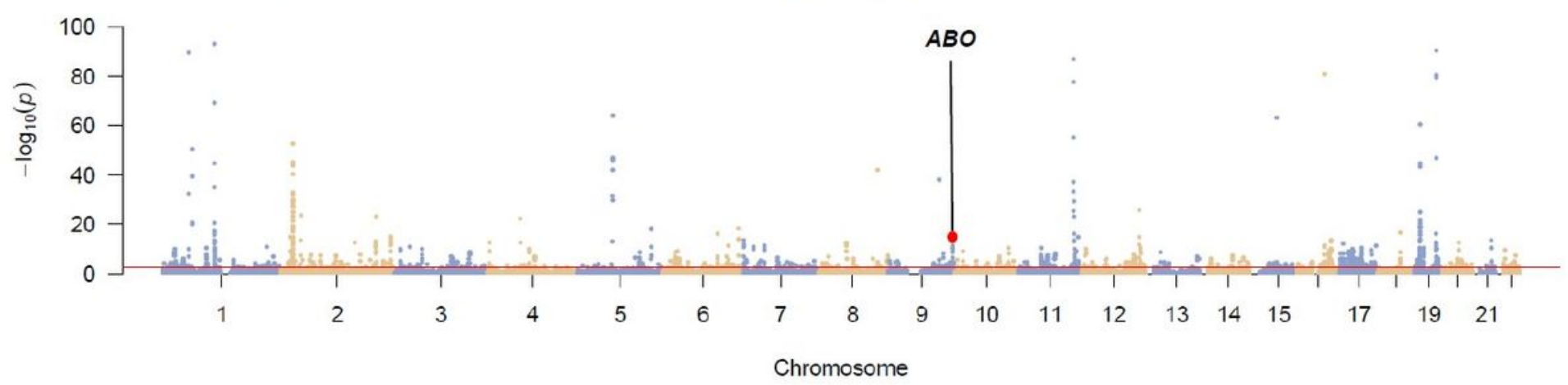

B.

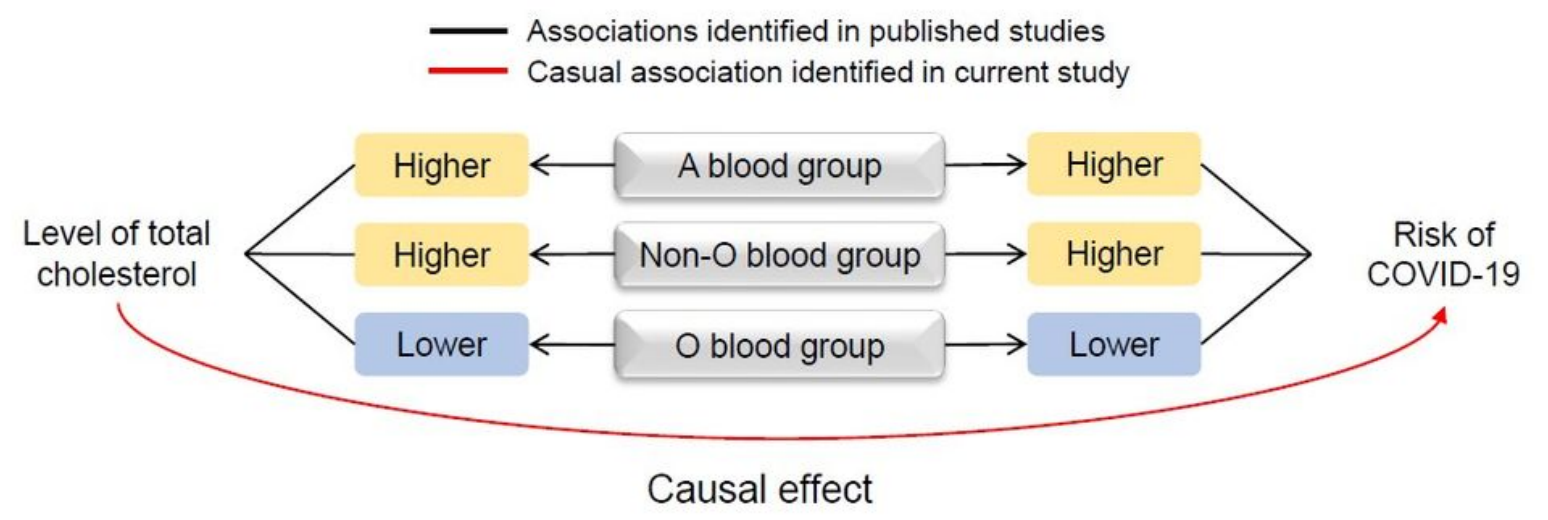

Figure 3

The relationships among the TC level, the susceptibility of COVID-19 and the different ABO blood group. A. Results of gene-based analysis. The dots above the red line represents the genes significantly associated (FDR $<0.05)$ with TC. The red dot indicates ABO gene. B. Schematic diagram displays the relationships among the level of TC, the risk of COVID-19 infection and different ABO blood group. Black lines represent the associations identified in previous studies and red line means the causal effect identified in our study.

\section{Supplementary Files}

This is a list of supplementary files associated with this preprint. Click to download.

- FigureS12.pdf

- Tables1S4.pdf 